\title{
Characterizing the Hsincheng active fault in northern Taiwan using airborne LiDAR data: Detailed geomorphic features and their structural implications
}

\author{
Yu-Chang Chan ${ }^{\mathrm{a}, *}$, Yue-Gau Chen ${ }^{\mathrm{b}}$, Tian-Yuan Shih ${ }^{\mathrm{c}}$, Chung Huang ${ }^{\mathrm{b}}$

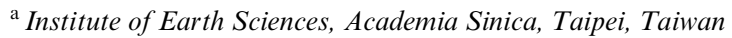 \\ ${ }^{\mathrm{b}}$ Department of Geosciences, National Taiwan University, Taipei, Taiwan \\ ${ }^{\mathrm{c}}$ Department of Civil Engineering, National Chiao Tung University, Hsinchu, Taiwan
}

Received 21 May 2004; received in revised form 18 September 2005; accepted 27 July 2006

\begin{abstract}
We applied newly acquired high-resolution airborne LiDAR data to study a segment of the Hsincheng fault, a well-known active fault near a large industrial park in northern Taiwan. The Hsincheng fault has received much attention and study in the past; but high spatial resolution digital elevation models have not previously been applied to the study of the fault and its surrounding structures. We processed the acquired LiDAR data and produced $1 \mathrm{~m}$ digital elevation models (DEMs) to investigate the active fault adjacent to the densely populated and important infrastructure in Taiwan. Using the LiDAR DEMs, aerial photographs and topographic maps, we show highly detailed geomorphic characteristics around the study area of the Hsincheng fault. Three major characteristics of the study area are defined that include three very well preserved river terraces at varying levels, the fault/fold scarp of the Hsincheng fault, and meandering river systems. Using the LiDAR DEMs, we were able to detect with precision several fault/fold scarps and very gentle NE-trending folding of the river terraces. In general, the LiDAR DEMs have provided unprecedented clarity of landforms for one segment of the Hsincheng fault, which has helped the characterization of subtle but important geomorphic features.
\end{abstract}

(C) 2007 Elsevier Ltd. All rights reserved.

Keywords: Airborne LiDAR; Digital elevation model (DEM); Hsincheng active fault, Taiwan; River terrace deformation; Fault/fold scarps

\section{Introduction}

Finding traces of active faults is often crucial for accurate assessment of seismic hazards. It is challenging, however, to locate active faults in densely populated cities or heavily forested regions such as on the island of Taiwan. For example, the1999 Taiwan Chi-Chi earthquake fault extended more than $80 \mathrm{~km}$ through urbanized parts of western Taiwan (Lee et al., 2002; Ma et al., 1999). The traces of the surface rupture indicated that previous fault or fold scarps were reactivated in the 1999 event (Chen et al., 2002; Rubin et al., 2001). This indicated the urgent need for better characterization of active geomorphic features in

\footnotetext{
* Corresponding author. Tel.: +8862 27839910x411; fax: +886227839871. E-mail address: yuchang@earth.sinica.edu.tw (Y.-C. Chan).
}

Taiwan to mitigate damage in future earthquakes. Because recent fault activity commonly involves subtle changes in topography, high precision elevation data are necessary to characterize recent faulting and folding, particularly in regions of high sedimentation rate.

The advent of digital elevation models (DEMs) has dramatically facilitated geologic and geomorphic mapping. For example, the Taiwan 40 by $40 \mathrm{~m}$ DEM with vertical resolution ranging from one to a few meters has been used intensively for characterizing the regional topography of Taiwan in the past decade. This $40 \mathrm{~m}$ DEM, however, is far from ideal for characterizing small scale strain provided in only one or a few earthquakes because of its low spatial resolution. In addition, the vertical resolution of the $40 \mathrm{~m}$ DEM cannot be used to define small elevation changes less than one meter in height. 
In this study, we processed airborne LiDAR (Light Detection and Ranging) data and derived high spatial and vertical resolution DEMs. We used the LiDAR DEMs to map a segment of the Hsincheng active fault in northern Taiwan (Fig. 1). The purposes of the study are to compare the acquired LiDAR DEM with the most commonly used Taiwan $40 \mathrm{~m}$ DEM, to demonstrate the applicability of the LiDAR-derived DEMs for detailed and precise landform characterization, and to investigate and refine the Hsincheng active fault and its surroundings near the Hsinchu industrial park. We emphasize that the LiDAR data have proven to be useful for detecting minor elevation changes of the study area, which is critical for evaluating and determining active structures of interest.

\section{The Hsincheng active fault}

The Hsincheng active fault is located near the Hsinchu science park in northern Taiwan (Fig. 1). The Hsincheng active fault was first confirmed by seismic profiling as a low-angle thrust fault. In contrast, the nearby Hsinchu thrust fault was revealed as a high-angle reverse fault (Fig. 2) (Chen, 1974; Chiu, 1970; Tang and Hsu, 1970; Yang et al., 1996). Our study area mapped only a small portion of the Hsincheng active fault. The Hsincheng fault was classified as an active fault based on the observations that the fault truncated Holocene river terraces (Bonilla, 1975). The Hsincheng active fault trends northeast, while the Hsinchu thrust fault trends east-west. The two faults merge at the Touchien river. Between the two faults is the Chingtsaohu anticline, a possible fault-bend fold (Namson, 1981). In recent years a spectacular outcrop of the Hsincheng active fault was exposed in the Touchien river due to erosion. The outcrop revealed the Hsincheng fault is thrust over recent river deposits, confirming the young activity of the fault. Trenching of the Hsincheng fault also indicated young activity: the Plio-Pleistocene Cholan Formation is thrust over alluvial deposits (Liu and Chen, 2003). In addition, trenching work also showed possible evidence of liquefaction from disturbed sediments of modern age. The phenomenon of liquefaction suggests seismic shaking potentially an earthquake on the Hsincheng active fault in the recent past.

\section{Airborne laser scanning techniques}

Lasers can measure distance with great precision; it is common that the errors of distance measurement are less than a few millimeters over distances about hundreds of meters (Huising and Gomes Pereira, 1998). Although laser

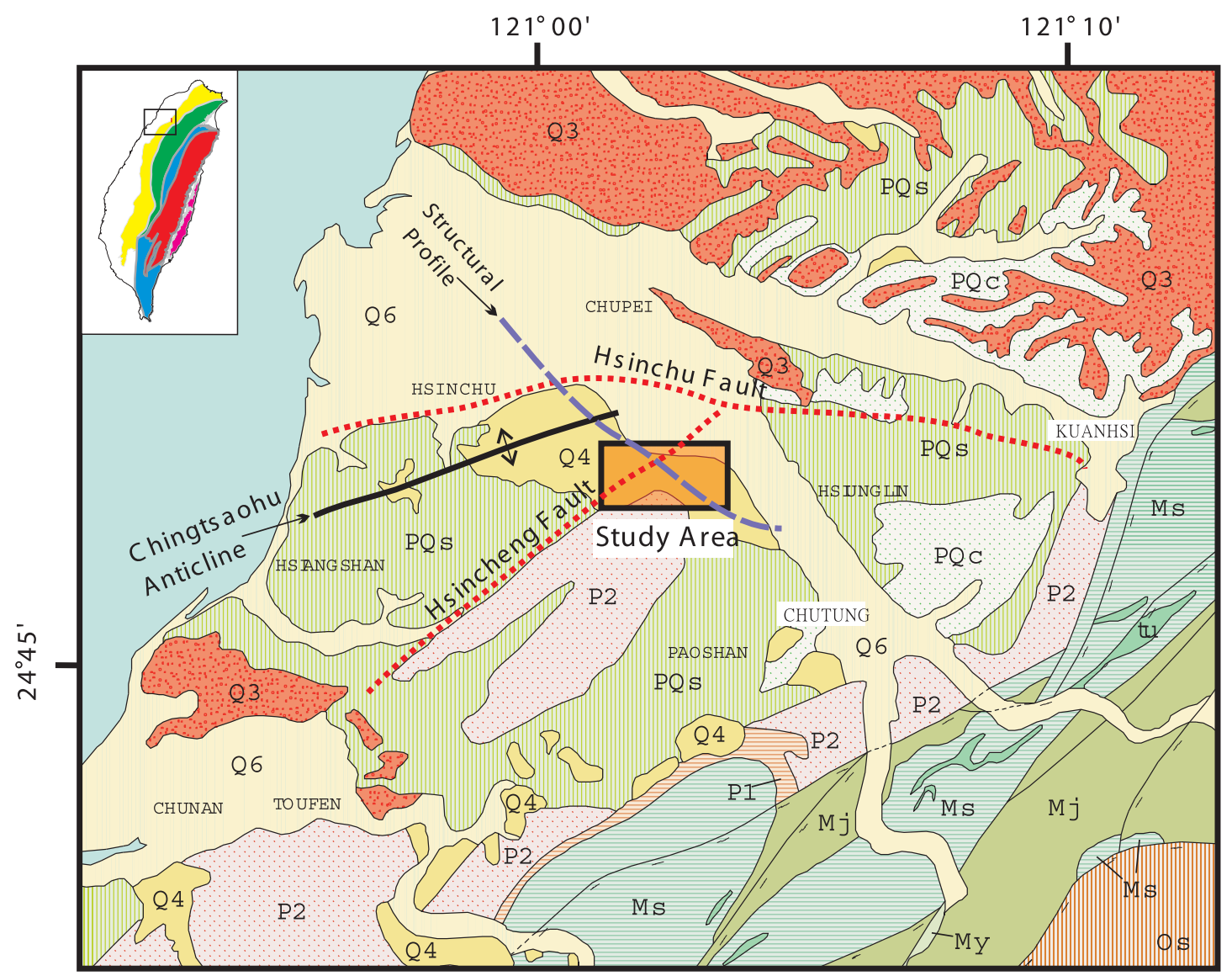

Fig. 1. Geologic map of the Hsinchu area by the Central Geologic Survey, Taiwan (CGS, 1989). Study area is indicated by orange box. Two major active faults were mapped in the region: the EW-trending Hsinchu fault and the NE-trending Hsincheng fault. Structural profile line for interpreted geologic profile in Fig. 2 is indicated. 


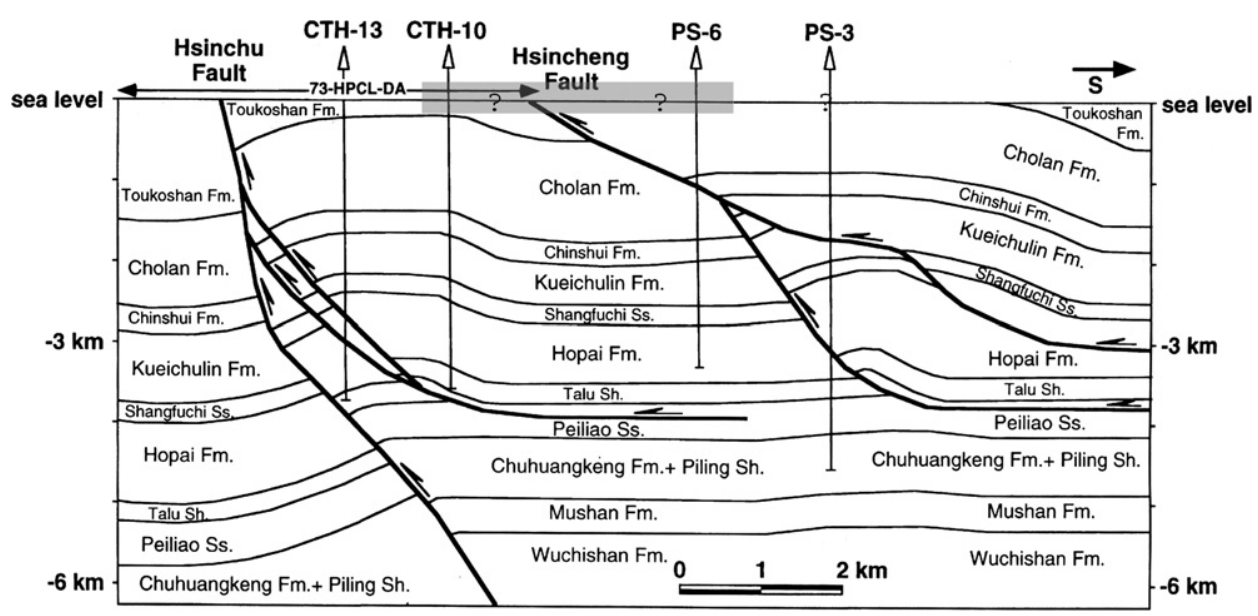

Fig. 2. Geologic cross section interpreted from seismic profile acquired by the Chinese Petroleum Company (Yang et al., 1996). The surface area of the Hsincheng fault examined in the LiDAR DEMs is shown.

technology has matured over several decades, the use of airborne laser scanning for mapping the ground surface was hindered by the accuracy of the position of the aircraft gathering the data. In the past decade, the introduction of differential GPS has improved the accuracy of the scanning platform. Airborne laser scanning now provides reliable and suitable spatial data for research applications (Carter and Shrestha, 2003; Haugerud et al., 2003; Wehr and Lohr, 1999; White and Wang, 2003).

The LiDAR data used for this study were provided by the Agricultural and Forestry Aerial Survey Institute (AFASI) in Taiwan. The LiDAR data of the Hsincheng fault region were acquired by the Leica Company using the LH ALS system during the spring of 2002. The flight height was $800 \mathrm{~m}$; the field of view (FOV) for scanning was 35 degrees; the scan rate was $29.4 \mathrm{~Hz}$; and the pulse repetition rate was $38 \mathrm{KHz}$. The Leica Company is one of the leaders in developing LiDAR technology for commercial applications. The acquired LiDAR XYZ data were further examined and compared by ground control points along highways using real-time kinematics GPS. The results of the comparison indicated that the vertical errors in the LiDAR data were $10-15 \mathrm{~cm}$ (Shih and Peng, 2002). The range of errors is suitable for high accuracy landform characterization and is particularly helpful for detecting small offsets resulted from past earthquake surface ruptures (Chan, 2005).

The raw LiDAR data was processed in several ways for the purpose of better characterizing the landforms. The raw LiDAR data commonly contain values of XYZ of a chosen reference coordinate system and values of intensity of the laser signal, whose wavelength is $904 \mathrm{~nm}$ and safe for human eyes. We processed and rasterized the LiDAR XYZ data with the method of inverse distance weighted interpolation (Swan and Sandilands, 1995). This method provides a fast algorithm for computing vast amounts of data and is suitable for the purpose of processing the LiDAR data. However, caution is necessary in applying the derived
DTM model. Areas with no real data points should be evaluated for interpolation errors before further use.

\section{Comparison of $40 \mathrm{~m}$ DEM and LiDAR DEM}

The commonly used $40 \mathrm{~m}$ DEM of Taiwan was generated by aerial triangulation using paired aerial photographs taken nearly two decades ago by the Agricultural and Forestry Aerial Survey Institute in Taiwan. The $40 \mathrm{~m}$ DEM generally possesses a vertical resolution of one to a few meters depending on terrain. Although the $40 \mathrm{~m}$ DEM is useful for geomorphic applications over large areas, it is unsuitable when detailed geomorphic analysis is required. For example, the study of minor surface offsets usually requires very high spatial and vertical resolutions. In contrast, the LiDAR-derived 1 by $1 \mathrm{~m}$ DEM provides unprecedented resolution for determining the surface profiles and relative elevations. In particular, the DEM derived from only the last laser returns helps identify the ground under vegetation and human construction.

The definition of a digital elevation model (DEM) may change for different applications. Here we use DEM as a general term, which contains both a digital surface model (DSM) and a digital terrain model (DTM). The DSM represents an elevation model that includes human construction and vegetation. The DTM represents an elevation model that has vegetation and buildings digitally removed and reflects the true ground surface. This appears to be useful for LiDAR-derived DEMs because the first returns and the last returns generally correspond to the DSM and DTM, respectively. In this study, we rasterized the first returns and last returns of the data points into DSM and DTM.

We note in examining the DSM and DTM, data points should be identified as either real or extrapolated. The situation becomes serious with the DTM because some areas may lack measured points, particularly where dense vegetation and buildings exist. This is examined by plotting all 
A

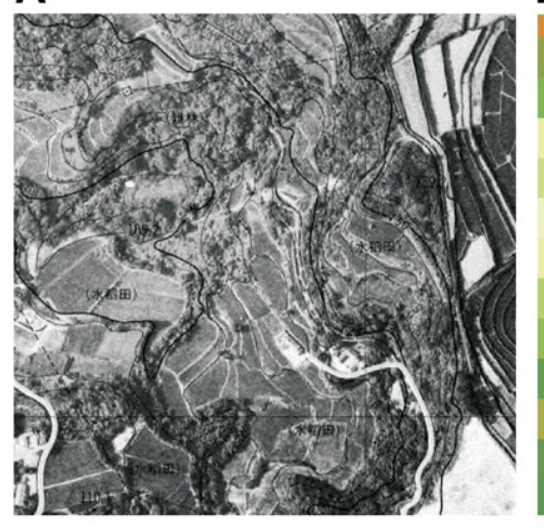

C

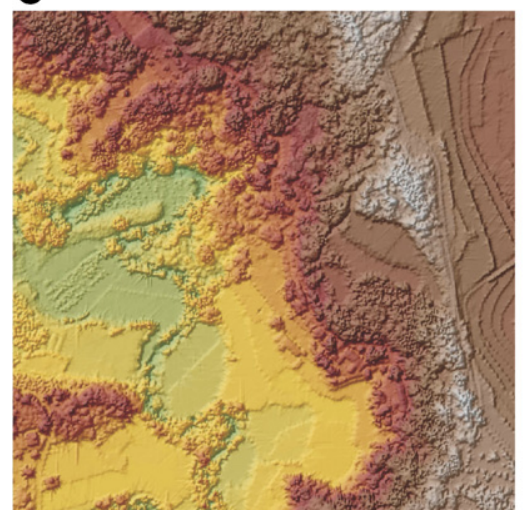

B

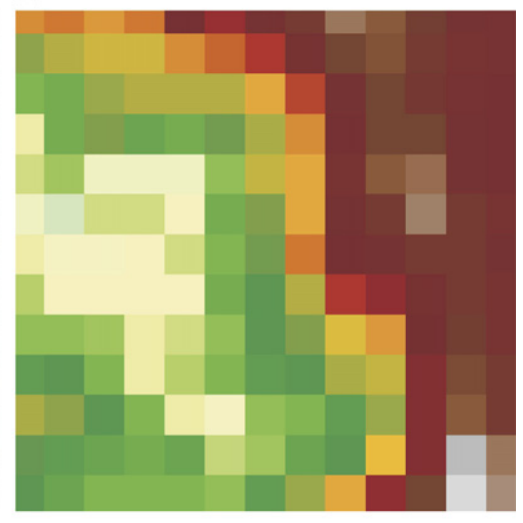

D

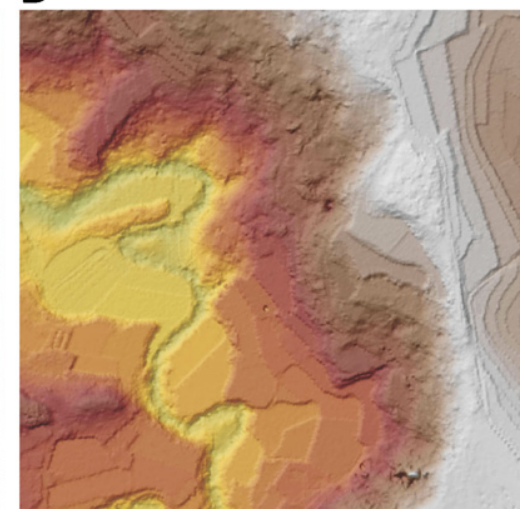

Fig. 3. Comparisons of $40 \mathrm{~m}$ DTM and $1 \mathrm{~m}$ LiDAR DSM and DTM for a $500 \mathrm{~m}^{2}$ site within the study area. (A) Orthorectified aerial photographs (B) $40 \mathrm{~m}$ DTM with color-coded elevation (C) $1 \mathrm{~m}$ LiDAR DSM shown as color-coded shaded-relief image. Notice the presence of vegetation. (D) $1 \mathrm{~m} \mathrm{LiDAR}$ DTM shown as color-coded shaded-relief image. Notice the effect of removal of vegetation.

data points of last returns onto georeferenced airphotos. We believe that, while analyzing landforms, particular caution should be applied to artifacts that arise from the interpolations at high resolution. Typically, the artifacts can be easily spotted in the DTM.

We compared the spatial resolution of the $40 \mathrm{~m}$ DEM with the LiDAR-derived $1 \mathrm{~m}$ DEMs within an area of $500 \mathrm{~m}^{2}$ within the study area. The comparison area was chosen because of high variability of the terrain which may help define the improved resolution of the LiDAR DEM. Within the comparison area are meandering rivers, terraces, and rice paddies (Fig. 3A). The $40 \mathrm{~m}$ DEM shows a 12.5 by 12.5 grid which fails to illustrate the terrain features (Fig. 3B). In contrast, the $1 \mathrm{~m}$ LiDAR DSM shows detailed surficial features including trees (Fig. 3C) and the $1 \mathrm{~m}$ LiDAR DTM captures the variability of the ground which is essential for detailed surface and geologic mapping (Fig. 3D).

\section{LiDAR images and geomorphic mapping}

The application of LiDAR data has improved the quality and efficiency of the characterization of active landforms in the Hsincheng active fault region. The existing 1/ 5000 aerial photograph-based topographic map shows detailed surface cultural features and vegetation of the region (Fig. 4). The topographic map, however, does not provide useful information for differentiating low-relief changes, which are essential for detecting recent tectonic activity. In contrast, detailed topographic features may be derived from the LiDAR DSM and DTM (Figs. 5 and 6).

Fig. 5 shows a color-coded shaded-relief image of the LiDAR DSM of the study area. The image was interpolated into a 1 by $1 \mathrm{~m}$ grid using the first return points. The image shows details of human construction and tropical forest canopy that contain important height information. Three locations of field photographs are marked on the LiDAR DSM in order to compare the LiDAR image of the actual size (Fig. 7). When in the field tectonic landforms were readily defined with the addition of the LiDAR DSM image. To examine potential recent tectonic activity of the Hsincheng fault, however, we created bare ground digital elevation models with virtual removal of buildings and trees using the Terrascan module on the Microstation software. Similar concept of virtual removal, i.e., virtual deforestation, has been developed and used on the Toe Jam Hill fault on Bainbridge Island near Seattle, Washington (Haugerud and Harding, 2001; Nelson et al., 2002).

Fig. 6 shows a color-coded shaded-relief LiDAR DTM image of the study area. The image was interpolated into a 


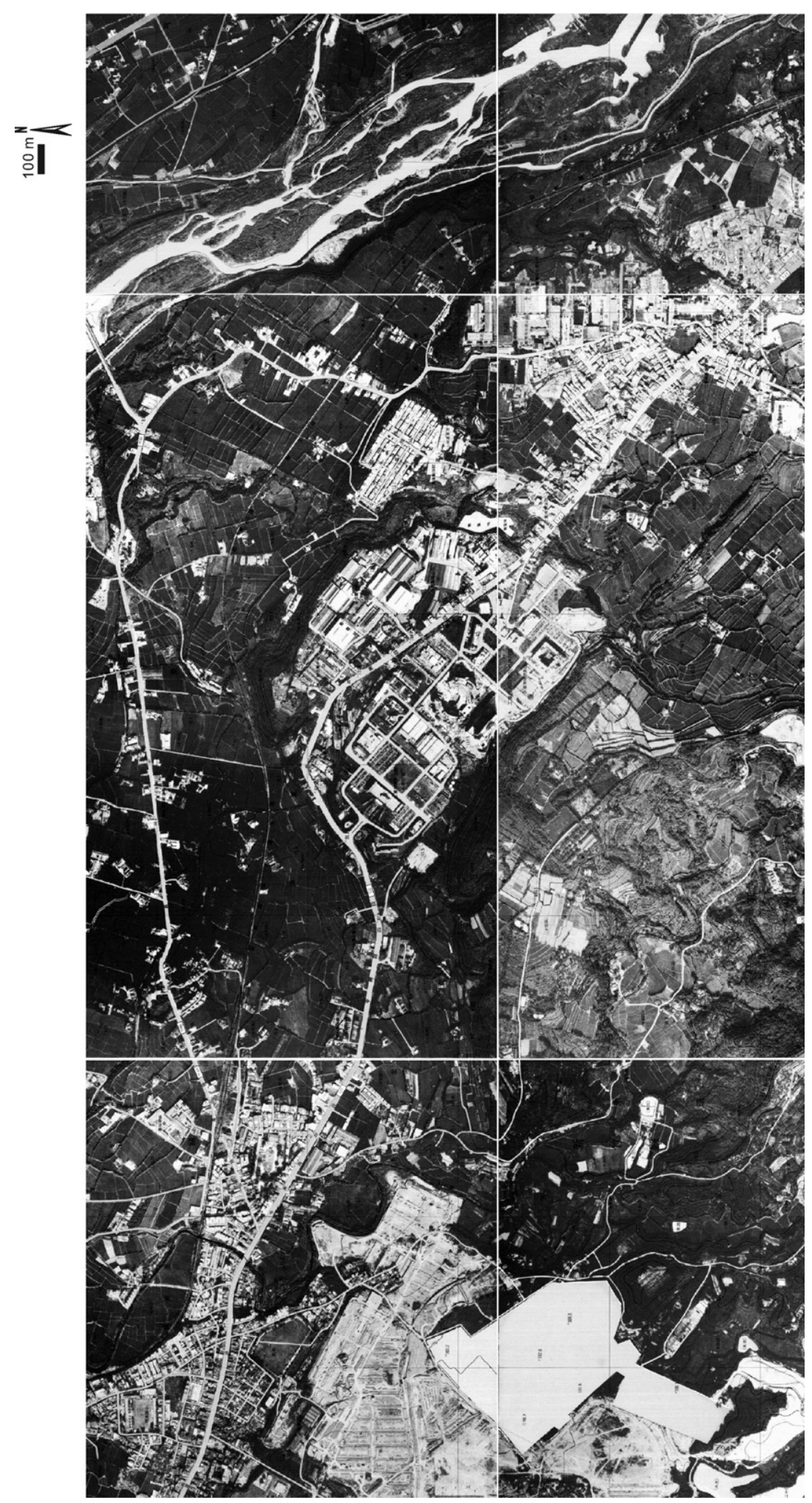

Fig. 4. Orthorectified aerial photographs of the study area provided by AFASI of Taiwan.

1 by $1 \mathrm{~m}$ grid using the last return points. The LiDAR DTM image shows the ground topography, which is most useful for the characterization of landforms and active structures. In this study, we used a black and white shadedrelief image of the 1 by $1 \mathrm{~m}$ DTM as the base map for geo- morphic and structural mapping. The LiDAR DTM does not, however, preclude the use of paired aerial photographs for stereo viewing and characterizing land features. Indeed, paired aerial photographs and LiDAR DTM were complementary to this study. 


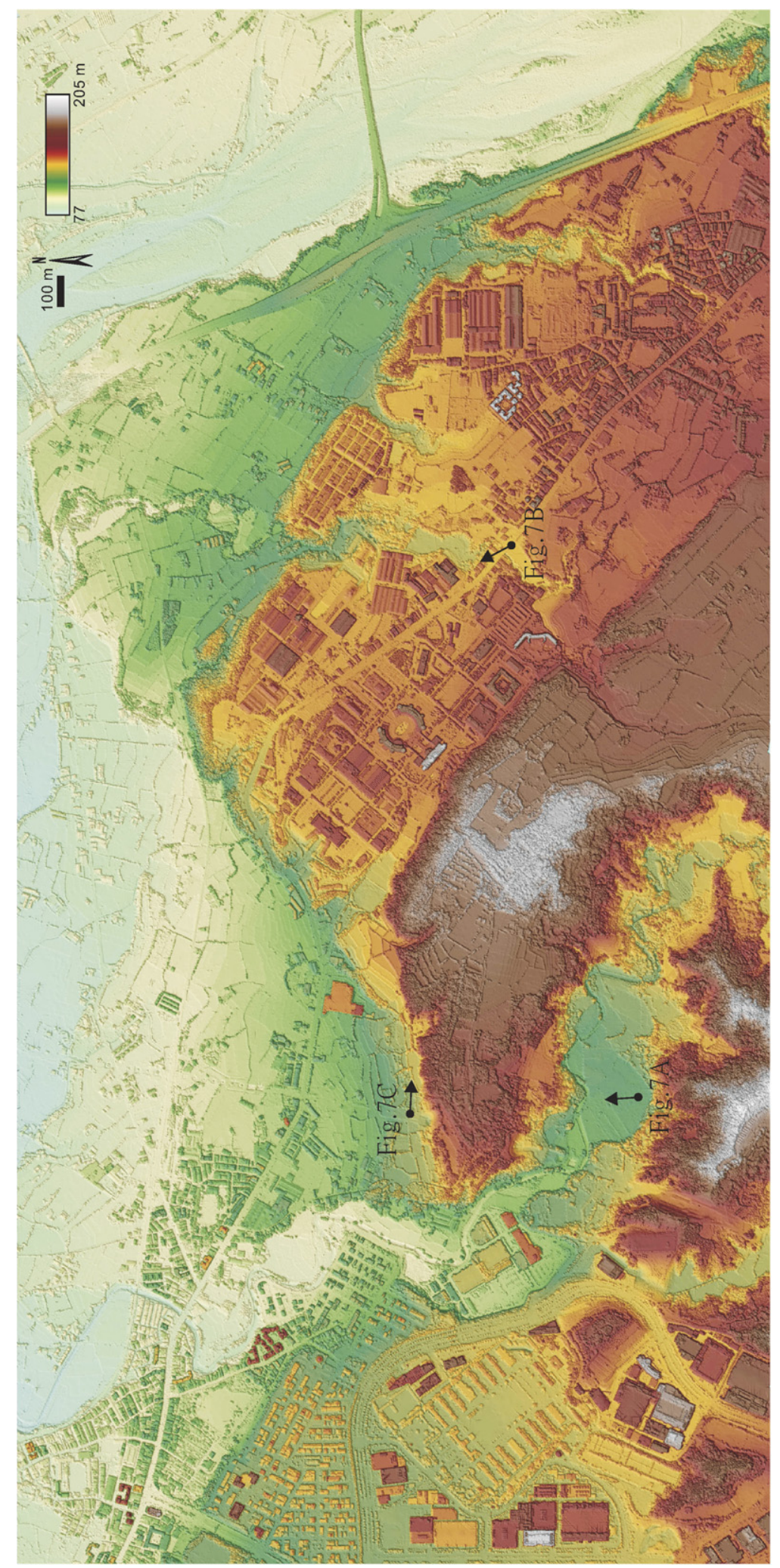

Fig. 5. LiDAR 1 by $1 \mathrm{~m}$ digital surface model (DSM) of the study area. The LiDAR first return data points were interpolated by the inverse distance weighted method. The interpolated grid data are presented as a color-coded shaded-relief image. Black dot with arrow represents the position and direction of field photos shown in Fig. 7.

Several terrain profiles were extracted and plotted from the LiDAR DTM (Fig. 8). Three creek profiles (Creeks I, II, and III in Fig. 6) show variation of creek slope at high reso- lution extracted from the LiDAR DTM (Fig. 8). Creek I runs across the structural trends of the region and meanders for a distance of about $5 \mathrm{~km}$. The elevation of the creek 


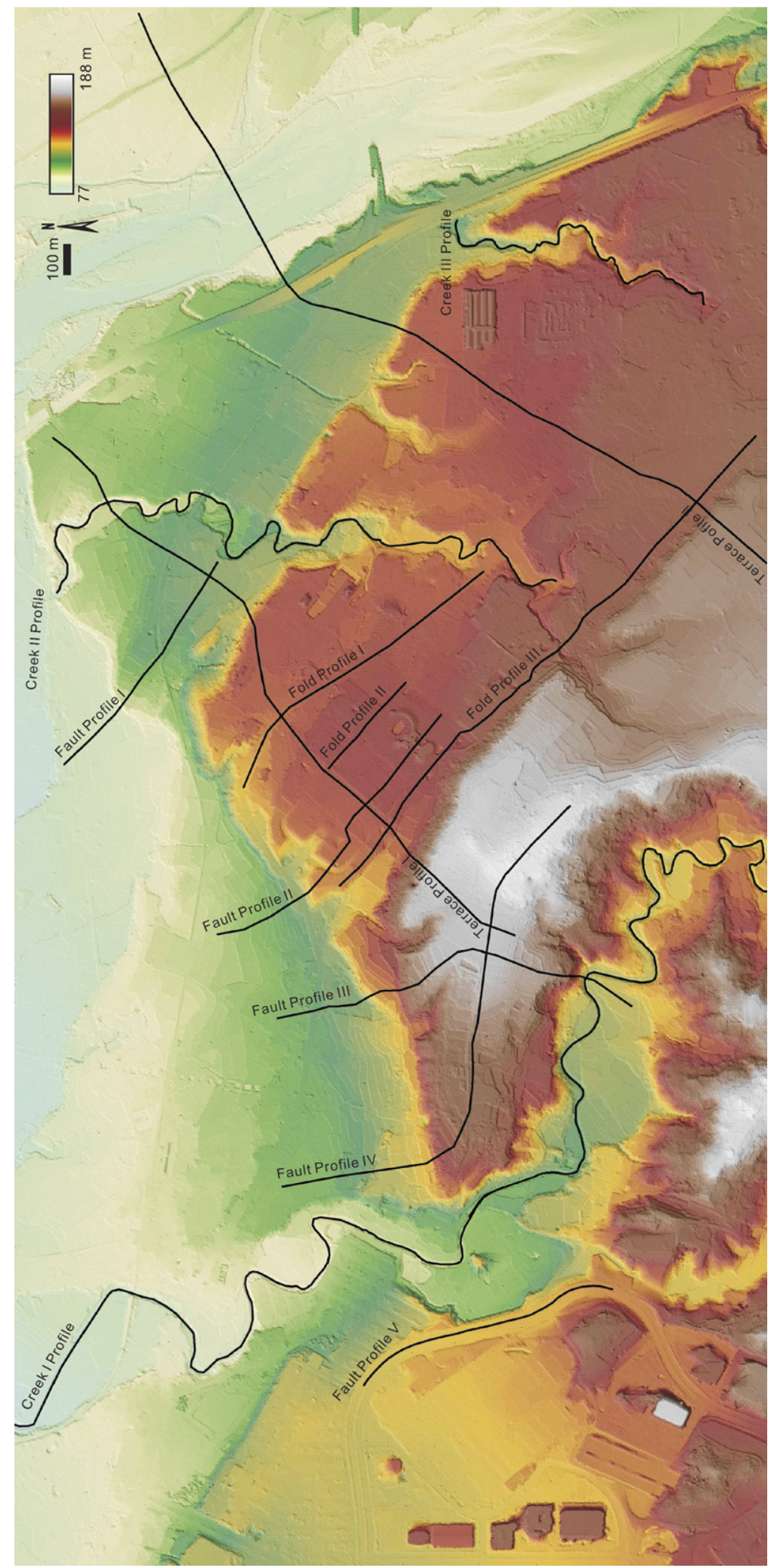

Fig. 6. LiDAR 1 by $1 \mathrm{~m}$ digital terrain model (DTM) of the study area for characterization of the bare ground. The LiDAR last return data points were interpolated by the inverse distance weighted method. The interpolated grid data are presented as a color-coded shaded-relief image. Black lines are locations of the profiles in Fig. 8.

drops from about $120-75 \mathrm{~m}$. Because of the high precision $(10-15 \mathrm{~cm})$ of the LiDAR elevation data, we were able to pinpoint two knick points around elevation 95 and $115 \mathrm{~m}$.
Two other creeks (Creeks II and III) are relatively short and they do not cross major fault lineaments in the region. If we disregard the high frequency feature of the creek pro- 

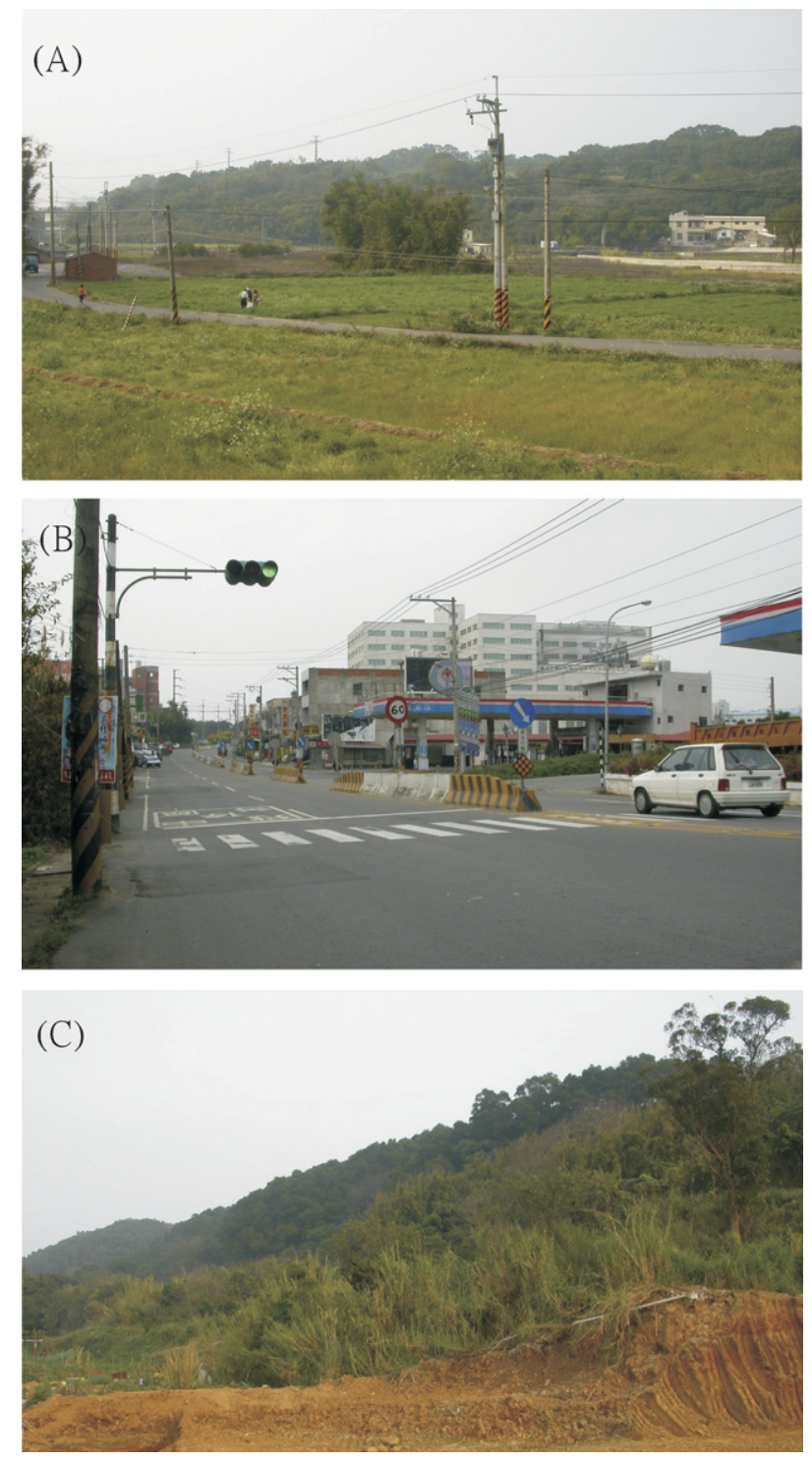

Fig. 7. Field photographs demonstrating the advantage of LiDAR for building and tree removal. See Fig. 5 for photograph locations. (A) Recent river terrace along creek I, (B) slope of road which represents the southeast limb of a gently folded terrace, and (C) a segment of the Hsincheng fault that offsets a high terrace. The height of the fault scarp is about 50 $60 \mathrm{~m}$.

files, the two creek profiles indicate relatively constant slope with local slight warping of unknown significance (Fig. 8).

Terrain profiles also were made across several locations of the Hsincheng fault (Fig. 8 Fault Profile I-V). We labeled fault scarps, fault branches, or fold scarps on the profile diagrams taking into consideration the overall terrain. The amount of offset of the river terraces due to the Hsincheng fault apparently increases from northeast to southwest. In addition, we made three terrain profiles to illustrate the gentle folding of the terrace where the campus of the Industrial Technology Research Institute is located (Fig. 8 Fold Profile I-III). Fold profile II particularly demonstrates the power the LiDAR DTM by depicting the geometry of the very gentle folding of the terrace.
We mapped geomorphic and structural features of the Hsincheng fault region using paired aerial photographs, LiDAR DSM and DTM, and field checking. Because of the high resolution of the LiDAR data, we mapped the geomorphic features with relative confidence and efficiency in comparison to only traditional methods. The final results of geomorphic and structural mapping (Fig. 9) show detailed features of river terraces, terrace slope, fault and fold scarps, anticlines and monoclines, and even minor diffuse terrace risers within well-defined terraces.

When significant changes are made by anthropogenic modification of low-relief topography, however, subtle fault traces may not be easily observed. For example, landforms in the western part of the study area were extensively modified by terracing for development of rice paddies and buildings. Thus, the modified topography no longer accurately records active tectonic features. In such cases, other methods of investigation must be applied, such as seismic or excavation surveys. We used the location of an excavated outcrop of the Hsincheng fault in the western portion of the study area (Liu and Chen, 2003) to extend the Hsincheng fault defined by LiDAR topography from the eastern study area (Fig. 9).

\section{Discussion}

Recently acquired LiDAR data were applied to the mapping and characterization of active faults and landforms in the Taiwan region for the first time (Chan et al., 2003; Huang et al., 2003). High-quality LiDAR DTMs are required for better investigation of active structures in Taiwan for several reasons. First, Holocene tectonic strain is commonly recorded through minor deformation of floodplains and river terraces. These geomorphic lowlands are best studied using a LiDAR DTM, which provides high vertical resolution of $10-15 \mathrm{~cm}$ in our study. Second, the LiDAR technology can record both the treetop return points and the bare ground return points. By removing the treetop return points and interpolating only the bare ground return points, a digital terrain model with vegetation virtually removed can be achieved (Haugerud and Harding, 2001; Nelson et al., 2002). Third, the Taiwan region is very densely vegetated, making DTMs a powerful tool for quantitative geomorphic analysis. Perhaps more importantly, our work shows that it is possible to digitally remove buildings, which has important implications for assessing subtle strain in densely urbanized cities.

Although the Hsincheng active fault has previously been recognized through geologic mapping and aerial photograph interpretation (Chen, 1974; Shih et al., 1985; Tang and Hsu, 1970), detailed geomorphic features of the region are most clearly demonstrated by the LiDAR DTM presented here. For example, the knick points of the Creek I profile correspond well with the mapped extension of the Hsincheng fault and subsidiary faults (Fig. 9). We interpret the knick point at elevation $95 \mathrm{~m}$ as the location of the Hsincheng fault. The location is consistent with a nearby 

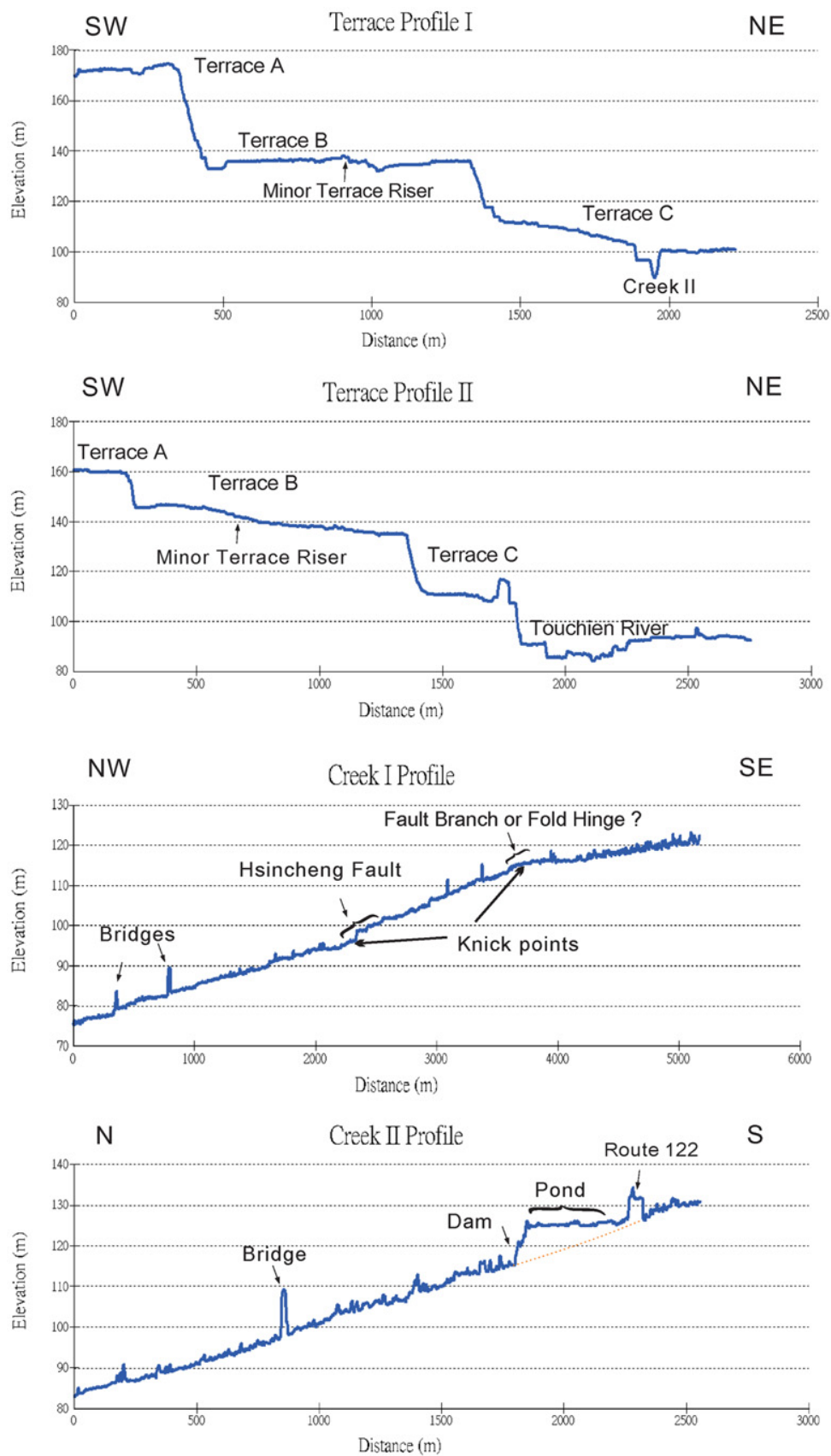

$\mathrm{N}$

Creek III Profile

$\mathrm{S}$

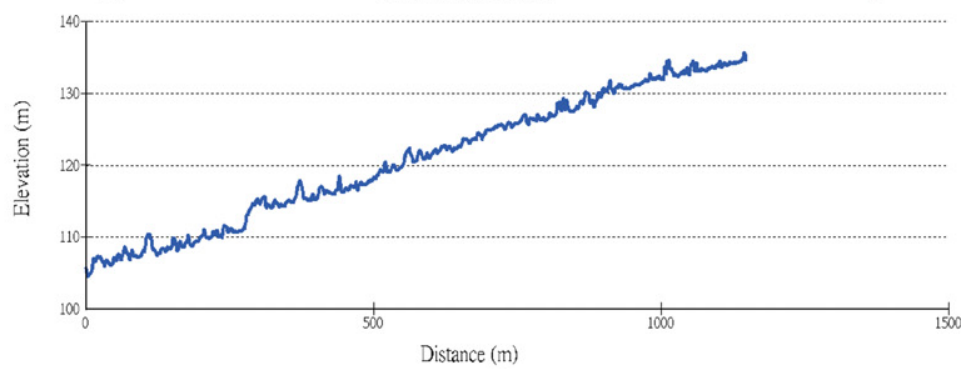

Fig. 8. Terrain profiles of selected features from the LiDAR DTM showing terrace profiles, creek profiles, and fold profiles of the study region. Vertical exaggeration is variable for each profile. The profile lines were selected so that the lines walk through the least artifacts of the LiDAR DTM. Particular features of the profiles are indicated within the profile diagrams. 

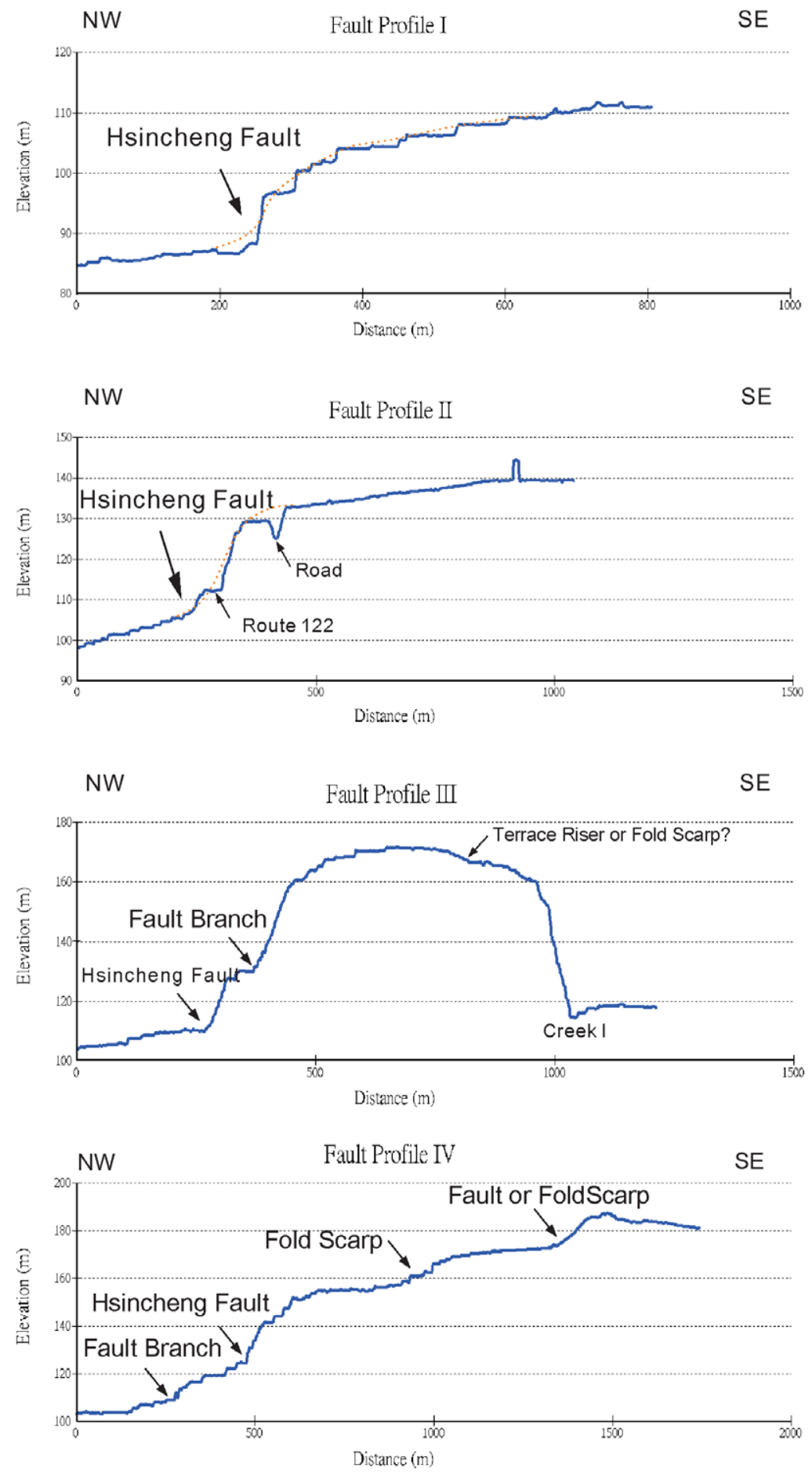

Fig. 8 (continued)

morphological scarp. We also interpret the knick point at elevation $115 \mathrm{~m}$ as a potential subsidiary fault branch in the region. The fault branch extends northeast and possibly displaces the oldest terrace of the study area (Terrace A).

The characterization of the Hsincheng active fault seems straightforward for Fault Profile I and II (Fig. 8). Certainly, some knowledge of modified features such as roads and rice paddies are necessary before interpretations are made from the profiles. The Hsincheng active fault is mapped on the basis of slope changes in profiles, interpreted as fault scarps. Examination of the profiles suggests that the Hsincheng fault is more complex in the southwest portion of the study area than in the northeast. The LiDAR DTM (Fig. 6) and the three terrain profiles (Fig. 8 Fault Profile III, IV, and V), are consistent with an EW-trending branch of the thrust fault that also offsets the ground surface. The possibility that this is a fluvial terrace riser can not be ruled out without subsurface investigation. 

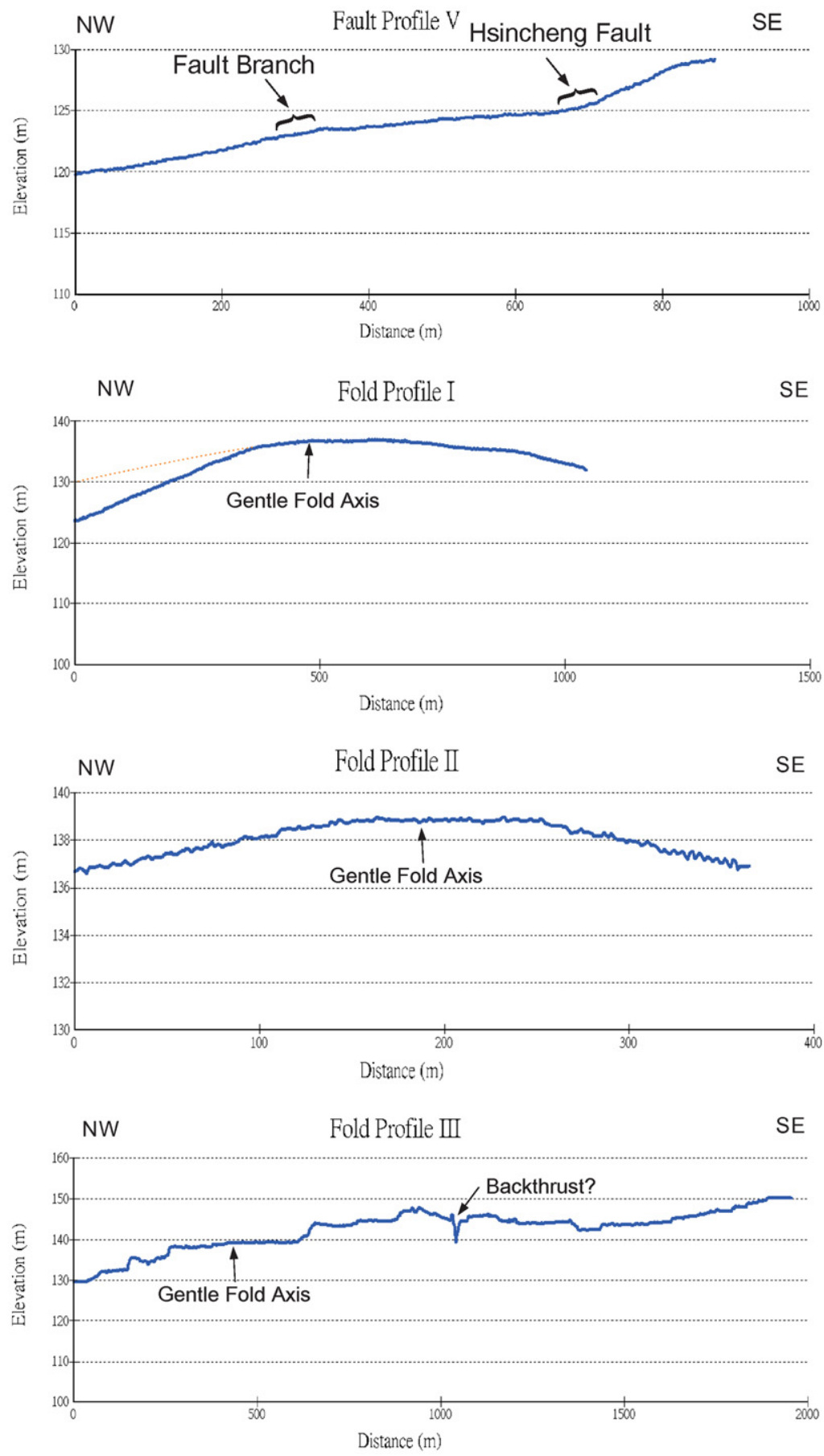

Fig. 8 (continued)

The above observations suggest that the Hsincheng and subsidiary faults are tectonically active. The rapid erosion rates of Taiwan likely would have smoothed the river profile of Creek I if the area has been stable. The presence of the gently folded terrace (Terrace B) also indicates the youthfulness of the structure. In contrast, Creek II and III profiles passed through two terraces without evidence of any fault traces. The creek profiles do not show obvious change of slope because the creeks lay between two faults. The observations are consistent with a regional pop-up structure interpretation (Fig. 10).
Geomorphic mapping of the Hsincheng active fault area identified several structural features. A back-thrust appears to be present between two gentle anticlines, although whether the back-thrust has emerged to the surface remains unclear. Along the Hsincheng fault scarp, several minor but obvious EW-trending scarps are also present. The orientations of these scarps are quite different from the flow direction of the Touchien river. We thus interpret these scarps to be subsidiary fault or fold scarps instead of terrace risers. Subsequently, the area of the Hsincheng fault shows two fault trends - the dominant system trends NNE, and the 


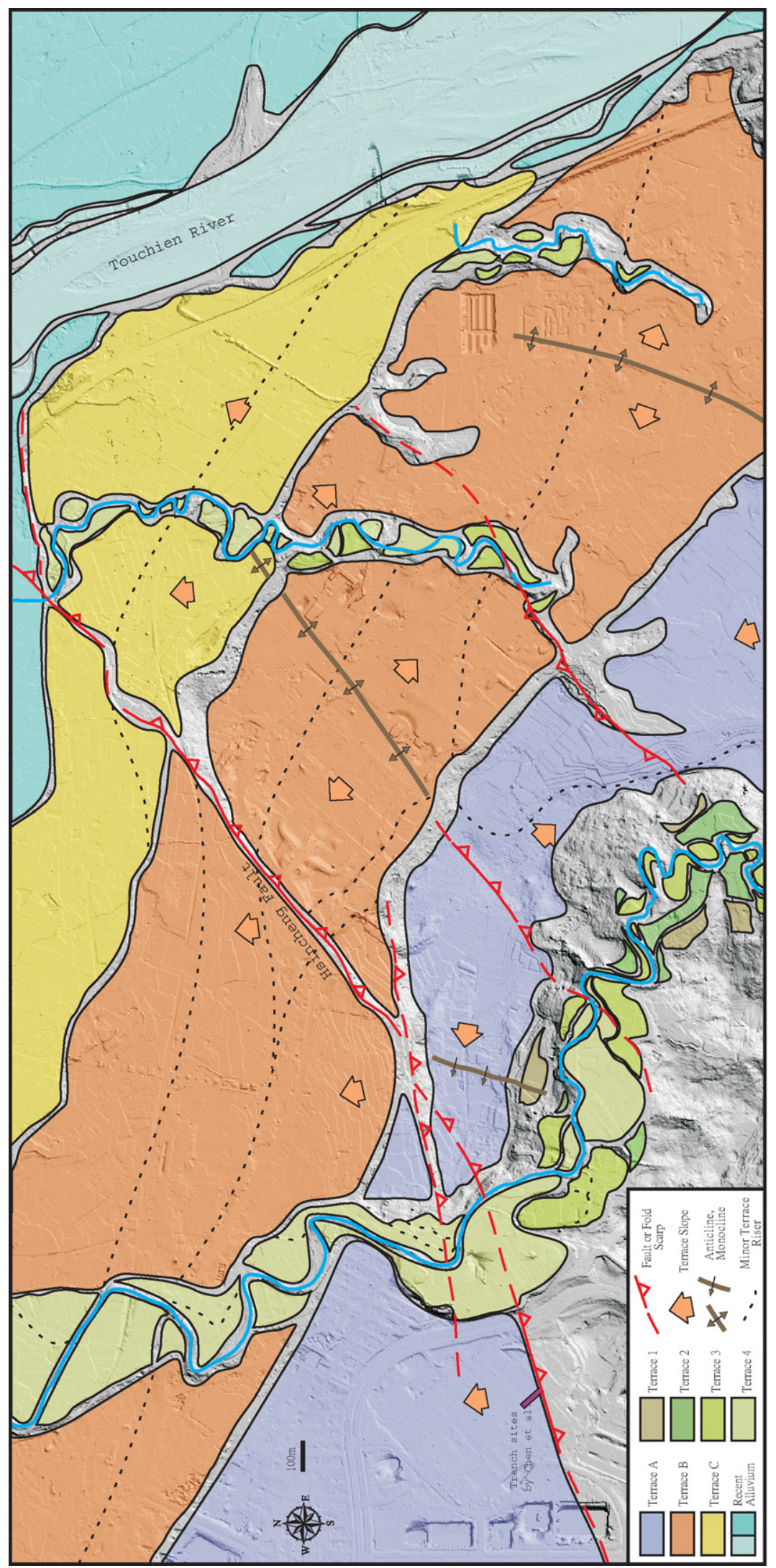

Fig. 9. Results of geomorphic and structural mapping of the Hsincheng fault region using paired aerial photographs, LiDAR DSM, and LiDAR DTM. See text for Section 6. 

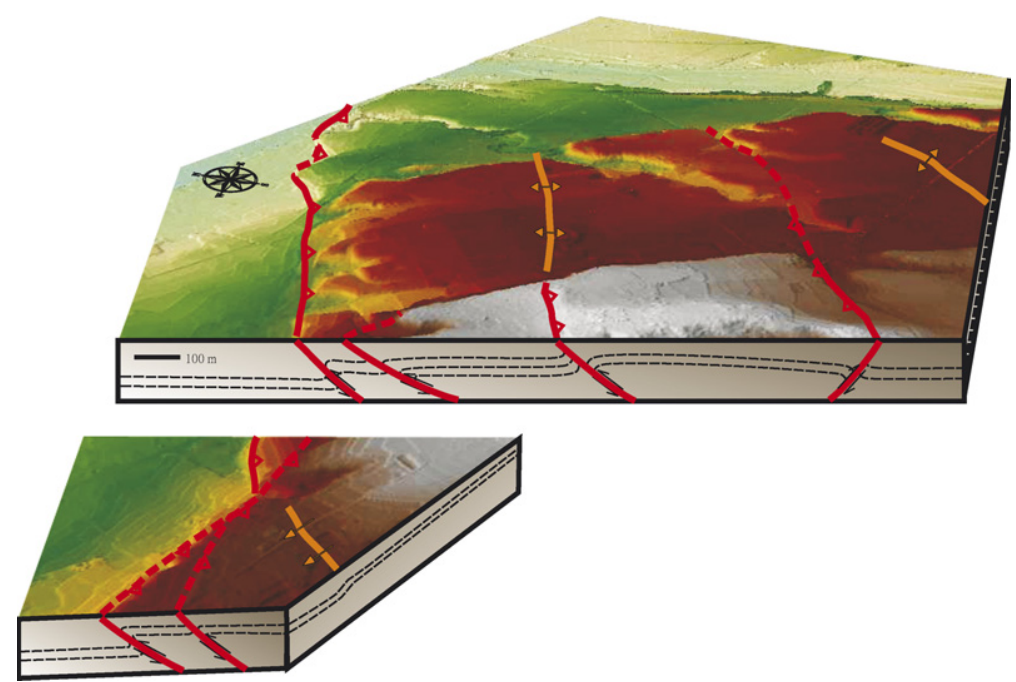

Fig. 10. Schematic block diagram showing structural interpretation of the Hsincheng fault and subsidiary structures. Block diagram was dissected to show a representative cross section perpendicular to the transport direction. The gently folded terrace and a potential buried back-thrust indicate a regional pop-up structure.

minor one trends EW. The mixed structural systems may result from interaction with the adjacent EW-trending Hsinchu thrust fault system (Yang et al., 1996; Chiu, 1970). The Hsincheng fault also may show apparent left-lateral movement as the offset of the terrace risers suggest. Judging from the non-perpendicular alignment of the terrace risers to the Hsincheng fault, it is kinematically possible to have such apparent left-lateral movement with a pure thrust fault.

During the course of making the LiDAR DEMs, we found it helpful to plot data points in conjunction with the derived LiDAR DEMs. This helps in the recognition of extrapolated areas of low data points and facilitates the interpretation of landforms. In general the LiDAR DSM has better quality than the LiDAR DTM because the surface data points are more complete and more homogeneously distributed than the ground data points. Thus we used the LiDAR DSM as a complementary tool to the LiDAR DTM, although the DTM is more suitable for landform characterization.

\section{Conclusions}

Airborne LiDAR data are important and practical for detailed analyses of structural and geomorphic features. On the basis of field observations and LiDAR DEM analyses, we presented a high spatial resolution structural and geomorphic map of the Hsincheng active fault region in Taiwan. We conclude that the widely used $40 \mathrm{~m}$ DEM of Taiwan may be of limited usage for analyzing subtle geomorphic features of small areas. Second, the LiDAR DSM, and especially the LiDAR DTM, appears to be powerful additions for the accurate and efficient analysis of active fold-thrust belts to traditional aerial photography methods. Third, the study area has many subsidiary structures that may be associated with the development of the Hsincheng fault, such as, a gently folded terrace and a regional pop-up structure. Fourth, the Hsincheng fault appears to be a major earthquake threat for the industrial park because detailed surface mapping and evidence suggest it has been recently active.

\section{Acknowledgments}

We thank the Agricultural and Forestry Aerial Survey Institute (AFASI) of Taiwan for providing LiDAR data for the purpose of our study. We also thank Jin-King Liu and colleagues at the Energy and Resources Laboratory, Industrial Technology Research Institute for their previous efforts on making the LiDAR test flight in Taiwan possible. The first author thanks Jian-Cheng Lee and Jyr-Ching $\mathrm{Hu}$ for providing comments and thoughts on the project. We thank Pamela Jansma and Stephane Dominguez for constructive and valuable comments. The research was partly supported by the National Science Council of Taiwan under Grant No. NSC92-2116-M-001-004 to Yu-Chang Chan. This is a contribution of the Institute of Earth Sciences, Academia Sinica (No. IESAS1131).

\section{References}

Bonilla, M.G., 1975. A Review of Recently Active Faults in Taiwan. Unites States Geological Survey, Menlo Park, USA. 58 p.

Carter, B., Shrestha, R.L., 2003. National center for airborne laser mapping proposed. EOS, 84. 281 and 285.

CGS, Taiwan Geologic Map $(1 / 50,000)$ - Hsinchu, 1989. Central Geological Survey of Taiwan.

Chan, Y.C., 2005. Introduction to airborne light detection and ranging (LiDAR). Science Development 390, 24-29. in Chinese.

Chan, Y.C., Chen, Y.G., Shih, T.Y., 2003. Using airborne LiDAR data to characterize the Hsincheng fault in Taiwan: detailed geomorphic features and their structural implications. 2003 Annual Meeting of the Geological Society of Taiwan Abstracts with Programs, pp. 594-598.

Chen, J.S., 1974. Seismic study of the Paoshan structure, Hsinchu, Taiwan. Petroleum Geology of Taiwan, 183-195. 
Chen, Y.G., Chen, W.S., Wang, Y., Lo, P.W., Liu, T.K., Lee, J.C., 2002. Geomorphic evidence for prior earthquakes: lessons from the 1999 Chichi earthquake in central Taiwan. Geology 30, 171-174.

Chiu, H.T., 1970. Structure features of the area between Hsinchu and Taoyuan, northern Taiwan. Memoir of the Geological Society of China, 63-75.

Haugerud, R.A., Harding, D.J., 2001. Some algorithms for virtual deforestation (vdf) of LiDAR topographic survey data: international archives of photogrammetry and remote sensing, 34, part 3/W4, Commission III, pp. 211-217.

Haugerud, R.A., Harding, D.J., Johnson, S.Y., Harless, J.L., Weaver, C.S., 2003. High-resolution LiDAR topography of the Puget Lowland, Washington - A bonanza for earth science. GSA Today, 4-10.

Huang, C., Chan, Y.C., Hsieh, M.L., Lee, J.C., 2003. Application of airborne LiDAR data to geomorphic characterization: an example from the 1999 ruptured Chelungpu fault in central Taiwan. 2003 Annual Meeting of the Geological Society of Taiwan Abstracts with Programs, pp. 594-596.

Huising, E.J., Gomes Pereira, L.M., 1998. Errors and accuracy estimates of laser data acquired by various laser scanning systems for topographic applications. ISPRS Journal of Photogrammetry \& Remote Sensing $53,245-261$.

Lee, J.C., Chu, H.T., Angelier, J., Chan, Y.C., Hu, J.C., Lu, C.Y., Rau, R.J., 2002. Geometry and structure of northern surface ruptures of the 1999 $\mathrm{Mw}=7.6$ Chi-Chi, Taiwan earthquake: influence from inherited fold belt structures. Journal of Structural Geology 24, 173-192.

Liu, L.H. \& Chen, W.S., 2003. Topographic analysis and trenching survey of the Hsincheng thrust fault. 2003 Annual Meeting of the Geological Society of Taiwan Abstracts with Programs, 15-16.

Ma, K.F., Lee, C.T., Tsai, Y.B., Shin, T.C., Mori, J., 1999. The Chi-Chi, Taiwan earthquake: large surface displacements on an inland thrust fault. EOS, Transactions 80, 605-611.
Namson, J., 1981. Structure of the western foothills belt, Miaoli-Hsinchu area, Taiwan. Petroleum Geology of Taiwan, 31-51.

Nelson, A.R., Johnson, S.Y., Wells, R.E., Pezzopane, S.K., Kelsey, H.M., Sherrod, B.L., Bradley, L.-A., Koehler, R.D.I., Bucknam, R.C., Haugerud, R., Laprade, W.T., 2002. Field and laboratory data from an earthquake history study of the Toe Jam Hill fault, Bainbridge Island, Washington, U.S. Geological Survey Open-File Report 020060, $37 \mathrm{p}$.

Rubin, C., Sieh, K., Chen, Y.G., Lee, J.C., Chu, H.T., Yeats, R., Mueller, K., Chan, Y.C., 2001. Post-earthquake response, 1999 Chi-Chi earthquake: evidence for past earthquakes. EOS, 82. 565 and 569.

Shih, T.T., Teng, K.H., Chang, J.C., Liu, M.C., 1985. Active faults and landforms around the Chutung tableland in Taiwan. Geography Research, National Taiwan Normal University 9, 1-16.

Shih, T.Y., Peng, M.H., 2002. Preliminary results of mapping earthquake hazard with airborne LiDAR system trials. 2002 Conference of Survey Engineering and Applications, Taiwan, A135.

Swan, A.R.H., Sandilands, M., 1995. Introduction to Geological Data Analysis. Blackwell Science. 446 p.

Tang, C.H., Hsu, C.H., 1970. Subsurface geology and petroleum deposits in the Hsinchu Area. Petroleum Geology of Taiwan, 89-101.

Wehr, A., Lohr, U., 1999. Airborne laser scanning - an introduction and overview. ISPRS Journal of Photogrammetry \& Remote Sensing 54, 68-82.

White, S.A., Wang, Y., 2003. Utilizing DEMs derived from LiDAR data to analyze morphologic change in the North Carolina coastline. Remote Sensing of Environment 85, 39-47.

Yang, K.M., Wu, J.C., Wickham, J.S., Ting, H.H., Wang, J.B., Chi, W.R., 1996. Transverse structures in Hsinchu and Miaoli areas: Structural model and evolution in the foothills belt, northern Taiwan. Petroleum Geology of Taiwan, 111-150. 